\title{
The Design and Use of Simulation Computer Games in Education
}

Edited by

Brett E. Shelton and David A. Wiley

Utah State University, Logan, USA 
cite as:

Shelton, B. E. (2007). Designing educational games for activity-goal alignment. In B. E. Shelton \& D. Wiley (Eds.), The Design and Use of Simulation Computer Games in Education (pp. 103-130). Rotterdam, The Netherlands: Sense Publishers.

BRETT E. SHELTON

\title{
DESIGNING EDUCATIONAL GAMES FOR ACTIVITY- GOAL ALIGNMENT
}

\author{
A perspective on how to improve current practices
}

\section{INTRODUCTION}

ALICE was beginning to get very tired of sitting by her sister on the bank and of having nothing to do: once or twice she had peeped into the book her sister was reading, but it had no pictures or conversations in it, "and what is the use of a book," thought Alice, "without pictures or conversations?"

What indeed, can we expect from our newest trend in education, implementing moving pictures and conversations with instruction through simulation games? Lewis Carroll's familiar narratives Alice's Adventures in Wonderland and Alice Through the Looking Glass provide helpful imagery for many of the queries, explorations and assumptions we currently make about this latest Wonderland of academia. So what are the goals for the designers and researchers of educational games, or perhaps more importantly, what should be the goals?

Perhaps not a goal in itself, a tenet of educational technology research is to develop and study new ways of utilizing technology to support effective instruction. Recently, using computer-based simulations and games in a variety of educational contexts has come to the forefront of this research agenda. Although there are several positions taken by game design researchers and instructional design researchers, most share a common focus: combining theoretical perspectives to design and develop technology-based tools for use in a variety of settings. These approaches have followed a number of models and have been supported through a number of scientific-based philosophies in education:

- constructionist building of knowledge (Barab, Hay, Barnett, \& Keating, 2000; Moshell \& Hughes, 1995)

- constructivist activity (Dede, 1995; Jonassen, Peck, \& Wilson, 1999; Roschelle, Pea, Hoadley, Gordin, \& Means, 2000)

- problem based learning (Barrows, 1986, 1996, 2002; Soloway et al., 2001)

- project based activity (Blumenfeld, Fishman, Krajcik, \& Marx, 2000; Fishman, Marx, Blumenfeld, \& Krajcik, 2004) 
SHELTON

- artifact-based, inscriptions and distribution of knowledge (Gordin \& Pea, 1995; Roschelle, 1992; Suchman, 2000)

In recent work, various technology researchers have used these approaches within their own definition of computer simulations and games, considering educational games as having intended learning outcomes that combine autonomous and interactive elements in a contrived environment (Davison \& Gordon, 1978; Hertel \& Millis, 2002; Jones, 1987). The action and interplay within the environment represents complex situations or phenomena and a level of social, distributed knowledge (deJong \& vanJoolingen, 1998; Windschitl, 2000). Other researchers have argued that this definition is an improvement over prior definitions, that fail to consider the potential and nature of social interplay between participants, the intended audience of the instruction, and the instructional objectives of the exercise (Shelton \& Wiley, 2006b).

The emerging theoretical approaches and the simulations and games derived from them show promise for helping educational technologists reach their goals of efficient, effective, appealing instruction for complex material (Shelton, 2003; Squire, Barnett, Grant, \& Higginbotham, 2004; Winn, 2002; Winn \& Windschitl, 2002). However, the field has yet to address how these resources are being designed and built to accommodate and be used advantageously by persons with varying abilities. I have received emails from teachers from around the world asking how to implement an educational game developed for use in their classrooms. One teacher from Pennsylvania asked how to use the game with "remedial readers" in her class of junior college students. Another instructor from Jakarta asked how he could use a game in his class of physically challenged students. Unfortunately, I did not have an informed answer for either of these questions. In this chapter I will argue that current approaches to using educational simulations and games are incomplete and have yet to bare the educational results of their potential. Further, very little attention has been given to a design consideration that should help map motivation to the instructional goals of educational simulations and games, while the potential exists to exploit the nature of these tools to address students with specific learning needs.

Therefore, by the end of this chapter, the need to clarify a basic approach directed at devising, designing, and developing educational simulations and games for persons with varying abilities should be made. Rather than viewing educational simulations and games as decontextualized artifacts existing independently of learners' interactions with them, appropriate strategies will allow the research to develop in ways that allow the resources to mediate the way both the designers and the users of the technology come to understand conceptual material. This learning process exists in contexts that include both formal and informal learning environments, addresses issues of universal design and usability, and integrates 
typologies of simulation game approaches that target specific cognitive challenges. ${ }^{1}$

\section{WHY TO WE NEED NEW FRAMEWORKS?}

\section{“Curiouser and curiouser!” cried Alice}

While instructors of multiple scientific disciplines are embracing educational computer games through a variety of philosophies and technologies, no rigorous frameworks for their design and use exist. In this section, I will explain current approaches to using educational games to facilitate learning, and contrast the assumptions of these approaches with current research. I will then characterize the design and development framework I believe is necessary for supporting the learning community more effectively.

\section{Current approaches to designing and using educational games}

Educational researchers and lay persons alike tend to believe the use of educational games can change the way students learn. But like other instructional media, educational games are only tools that enhance learning when designed and implemented in accordance with principles of effective instruction. Two approaches to designing and using educational games in the context of these principles currently dominate the published literature and conference presentations. Some researchers advocate an approach rooted in game design theory, emphasizing the educational importance of motivating and engaging learners (Zimmerman \& Fortugno, 2006). Others advocate approaches rooted in instructional design, creating meaningful activities that are somehow driven by and assessed through traditional means (VanEck, 2006). Yet many scholars, myself included, believe the most appropriate approach lies at the intersection of traditional game theory and instructional design theory.

Undoubtedly, the people interested in games research who work in different disciplines have vastly different perspectives on what is important in making these games instructionally effective. It is a Mad Hatter's tea party of researchers with just as many opinions. But even within this huge diversity of interests, few if any researchers have worked to bring the benefits of these approaches to underserved groups. Many students are not afforded the same opportunities to use instructional

\footnotetext{
${ }^{1}$ For the remainder of this chapter, I will use the term "educational games" when describing the spectrum of computer-based tools that include instructional simulations with game-like elements and educational games with simulation-like qualities. I recognize the many differences in how genres of computer-based simulations and games can address different aspects of learning, and can be dissimilar in a number of other respects. However, I will use the term "educational games" in the effort to be inclusive of most types and to maintain clarity and brevity throughout my arguments.
} 
SHELTON

games due to their physical or cognitive disabilities, and the limitations of the educational tools themselves. Even more glaring, a balance between building motivational, engaging games has not converged with the kinds of promising learning outcomes desired by most educators who use games in their teaching. So, what are the important research questions, and what is it that we as educational technologists can do to address these challenges? I believe we should begin by adopting a position of skepticism instead of being educational games advocates. Too many assumptions remain about what games do and to what advantages we can use them. Cuban (1986) highlighted the utter disappointments of the realized potential of each new technology and how its use would change the face of education, how it's practiced, and how students will learn since 1920, and thus far we should add educational games to the list. The assumptions are many, and are indicative of how games:

- Can help people teach. Most evidence has been contrary to this notion thus far, in that instructors have little time to prepare lessons around the use of games for classroom use, or are not gamers themselves, or do not have enough instructional support, or cannot align them with state and national standards (Kirriemuir, 2002, 2003; Kirriemuir \& McFarlane, 2003; Shaffer, Squire, Halverson, \& Gee, 2004).

- Can help people learn about complex relationships and phenomena. The evidence exists to support this notion within contextualized pockets and in situ experimental situations, but has yet to be implemented across multiple contexts or at any reasonably large scale (Barab, Hay, Barnett, \& Squire, 2001; Hayes, 2002).

A sound philosophy of research-into-practice includes many of the questions that echo those of Squire (2002), when he advocated a learning sciences approach to studying educational games, looking to the kinds of activity that go on within and between individuals and the artifacts they use to develop understandings of complex material. We still know little about how these understandings translate to the "real world" and if and when they are applicable. We know little about the impact of these games and how they can align with more formal learning environments. The development of hybrid theories and approaches to learning-type games are necessary to advance the field. The creation and study of games based on these hybrid theories is crucial. Therefore, the continual questioning of the existing assumptions is important to better understand if and how instructional games can and should be used within formal and informal educational environments. 
Parallel to the issues of using computer games effectively in traditional schoolbased environments is an issue with the design and development cycle for building educational games for students with learning disabilities, even while preliminary evidence suggests that some of these tools have the potential for effectively addressing specific impairments. Diggs (Diggs, 1997) offers a case that shows how computer technology, including educational games, helped a fourth grade student with learning disabilities and behavioral disorders begin to succeed academically and to interact with his peers. Other researchers discuss the benefits of educational games for cognitive impairments, including the increased motivation of learners and the ability to customize the tools for specific types of challenges (Blum \& Yocom, 1996; Shiah, Mastropieri, Scruggs, \& Fulk, 1994). Additional research has suggested that these types of activities help students with learning disabilities in areas of writing, memory tasks, geography and the application of problem-solving skills (Conderman \& Tompkins, 1995; Okolo, 1992; Welch, 1995). While most studies indicate the potential of these tools, not all of the evidence is in agreement. Christensen and Gerber (Christensen \& Gerber, 1990) indicate that a non-gamelike approach was more effective for cognitively impaired students for a drill-andpractice exercise, perhaps due to the distractions and load of the non-instructive elements of the activity. These studies exemplify the potential of educational games for students with learning disabilities with a special eye toward the proper design and implementation.

\title{
ELEMENTS OF EFFECTIVE INSTRUCTIONAL GAMES
}

\author{
"A cat may look at a king," said Alice. "I've read that in some book, but I don't \\ remember where." \\ "Tut, tut, child!" said the Duchess. "Everything's got a moral, if only you can find \\ it." And she squeezed herself up closer to Alice's side as she spoke.
}

\section{Disparities between educational games approaches and current research on learning}

When discussing the use of educational computer games in formal learning environments, it is helpful to distinguish between three types of games. The first, which might be termed "entertainment games," includes computer games designed for entertainment purposes that are "repurposed" in the context of lessons. For example, SimCity 3000 and Age of Empires, commercially available games, are used as tools in the classroom to teach students to understand complex, dynamic models (e.g., community planning and geographic placement of services) and to improve thinking skills (Agency, 2001). The games' entertainment value has been used to motivate students to participate in the learning activity, and the game activity has been repurposed into a lesson. One downside of this approach is that much of the substantial "learning" that is reported is secondary or unintentional (Kirriemuir \& McFarlane, 2003). Secondary or unintentional learning occurs when 
a player learns concepts or skills not associated with the goals of the activity. Examples of unintentional learning are acquiring social skills from participating in the game environment, learning how to better use the controls of the game, or gaining an understanding of what abilities the arch nemesis has. To clarify, it is not that unintentional learning cannot be beneficial, it is more that within a structured learning environment in which specific learning goals are intended, unintentional learning is not very helpful. And from a designer's perspective, it is not useful.

The second type, which might be termed "reward games," includes games explicitly designed for education that rely on "reward" systems to motivate students in the learning activity. The reward systems are not associated with learning activity, but rather act as a means to an end so that the player is rewarded for "correct" behaviors. These games often come in the form of basic skill practice such as a typing tutor in which the reward system may become the focus of the game or a distraction from the learning activity. An example in this category is drill-for-skill games like many of those in the Jumpstart series. The success of these games is limited to reinforcing recognition and response times through practicing repetitive procedures. One downside of this approach is that "reward" systems may not have enough motivational power to help learners reach complex instructional or reflective goals. Other arguments suggest that "rewards" games are more effective for less complex kinds of cognitive practices, or that excessive rewards may lead to activity that actually detracts from the learning objectives, which is common to the third type of game.

The third type, which might be termed "distraction games," includes those that are specifically designed for learning but contain overwhelming levels of gamelike attributes that ultimately distract the players from the learning objectives (Kirriemuir, 2003). For example, Supercharged! is an educational game designed to teach students about electromagnetic fields. Squire et al. (Squire et al., 2004) found that some students struggled to achieve a deep understanding of the activity's non game-like components. Some students felt more compelled to "win" the game, rather than the activity associated with "winning." Therefore, attempting new strategies or playing the complementary levels to learn about electromagnetic fields was less interesting. Research suggesting why this third category of games has failed to reach its expected potential also suggests what might be done to develop games that lead to effective learning. Shelton (2005) suggested the potential of using computer games for instruction may be observed by understanding the problems associated with their design. Working to align game activities with instructional goals may help balance the motivations for playing the game. Findings from this research suggest that the problems with some games may not be found in the idea of gaming but how the games are structured or aligned with their learning objectives.

\section{Toward a new theoretical framework}

In prior work with partial funding from the state of Utah, I have attempted to describe both ontological and functional aspects of educational games. This work 
continues based on identified elements of learner-player motivation--the first three based on modified video game motivation elements (Lepper \& Chabay, 1985; Malone, 1980; Malone \& Lepper, 1987; Shelton \& Wiley, 2006b) and the final on social interaction analysis (Steinkuehler, 2003; Steinkuehler \& Chmiel, 2006):

- challenge - the gamer is provided a goal, and activities (neither too complex nor too simple) are required to make progress within a situation or environment

- proclivity - an environment that holds a personal interest, drawing an individual toward the subject matter in a way that sustains interest

- uncertainty - imagining a number of possible outcomes to an activity, and the desire to want to reach an attainable stopping point which requires a measure of persistence

- social interaction - peer collaboration is an effective way for a child with low ability in learning, paired with a child of high ability, to lead to cognitive benefits for both children (Fawcett \& Garton, 2005)

Aldrich's six criteria for what counts as an educational simulation (2004a; 2004b), based on the Virtual Leader simulation and surrounding project, are divided into two categories that describe the delivery elements of the simulation and the type of content within the simulation. His delivery criteria are simulation, game and pedagogy; his content criteria are systems, cyclical and linear. However, some have argued that his described delivery elements fail to adequately emphasize the role of intelligent participants within the simulation. Further, his criteria of pedagogy does not provide an emphasis on the issues that surround learning, including the way information is represented, and aspects of cognitive load. ${ }^{2}$

Based on a working perspective of what an effective educational simulation does, I define an effective educational simulation as: with the intention of helping learners achieve desired outcomes, an instructional simulation combines autonomous and interactive elements in a contrived environment that represents complex concepts or phenomena of the real world. Outcome measures and advantages include the ability for the student to learn at their own pace, the student is able to retain and apply what they learned, and the educational game is accessible to multiple learning styles. Using the criteria from Aldrich as a starting point for defining the elements of effective instructional simulations, I emphasize the pedagogy and engagement factors within the simulation scenario of what makes for essential criteria:

- Addresses a learning issue

- Complex - requiring a level of depth beyond what one sees in simple "walk-through instruction"

\footnotetext{
${ }^{2}$ With Aldrich's content types, I assume they only specify a computer-based environment that also provides simulation-like features of repeatability, scalability, and cost-effectiveness. However, I am unsure if this assumption is warranted.
} 
- Intentional - directed instruction aimed at identified problems, but may be exploratory in nature

- Contains learning objectives or goals

- Explicit or implicit, depending on how they fit within the flow of the scenario

- Includes participants with constraints (rules)

- Not observers, requires a level of interaction

- Includes an environment with constraints (rules)

- Contrived for other-world experiences, and/or

- Mimics real-world processes, sequences, etc.

- Operates by a facilitating mechanism - includes required hardware, software, and non-computer based resources

- Requires activity

○ Interactive (contains feedback, adaptation, choice)

- Autonomous (embedded information)

- Based on non-random outcomes

- Sequences of events produce a predictable outcome, ultimately tied to learning goals

- Events within a scenario may have random qualities

- Repeatable (different choices may produce different outcomes)

In addition to the essential criteria listed above, I recommend keeping other design criteria in mind as well in order to take full-advantage of what educational games may offer:

- Scalable

- Internal - the simulation may be expanded to include multiple players

- External - the platform may be developed to include multiple scenarios based on similar instructional objectives

- Contains representations not possible / affordable to experience in the "real world"

- Cost-effective

These definitions and criteria have assisted in forming a grounded basis for analyzing educational simulation games in a variety of settings. Through this experience, research such as that contained in this volume may continue an effort for the merging of philosophies and approaches from industry training, game design theory and instructional design theory to help inform the designers and developers of technology and games-related. Using these definitions and criteria, researchers may choose to turn a special eye toward how these tools are used by persons with varying abilities as they mediate their understanding of complex concepts and phenomena. This emerging broad base of educational games research, such as that within this volume by Nelson et al., Squire et al., Barab et al. and Steinhuehler, positions the field well to carry out the proposed activities. 
I believe that a more rigorous understanding of the ways in which learners actually use educational games, that is, a more rigorous understanding of the ways that educational simulations and games mediate educational activities, will provide significant value to science, mathematics and technology education for persons with differing abilities. This increase in understanding will serve to launch a very productive course of educational technology research. In the next section, I provide an example of students using educational games for problem solving activities.

\section{ACTIVITY-GOAL ALIGNMENT THEORY}

Once more she found herself in the long hall, and close to the little glass table. "Now, I'll manage better this time," she said to herself, and began by taking the little golden key, and unlocking the door that led into the garden. Then she went to work nibbling at the mushroom (she had kept a piece of it in her pocket) till she was about a foot high: then she walked down the little passage: and then--she found herself at last in the beautiful garden, among the bright flower-beds and the cool fountains.

Alice eventually learns that in Wonderland, the keys she finds fit the doors she is supposed to enter, and eating just the right amount of mushroom will make her the proper size to move forward. In fact, she is learning from her environment what the important things are to attend to. So is what we learn from studying those who play games truly beneficial, worthwhile, and valid? Shaffer et al. (Shaffer et al., 2004) write that games are changing the way we learn by giving players the opportunity to participate in different game-created worlds and to learn by doing. Education researchers suggest the use of computer games may help transform the way students think about their world (Holland, Jenkins, \& Squire, 2003; Steinkuehler, 2003). The bulk of the evidence suggests that computer simulation games can be used to increase student motivation, teach problem solving strategies, and help students understand the meaning of context (Gunter, 1998; Hayes, 2002). I generalize that educational games may provide learning benefits if the beneficial potential games offer can be organized into the game itself, and into the social activity surrounding the game. What we learn from playing educational games is truly beneficial only when they are designed according to valid principles of effective instruction. We need frameworks to understand what these principles are.

River City, developed at Harvard by Dede, Ketelhut, and Nelson (2004), represents players as an avatar in a virtual world with the purpose of finding out what is causing a disease in a local town. When beginning the game, the players may choose the name of their avatar as well as their character. The creators of the game designed a particular character after Ellen Swallow, the first woman to graduate from MIT with a chemistry degree, with the intent of increasing motivation for female players. While these game-like characteristics were added to enhance the experience of the player and create high levels of motivation, they also 
have the potential to distract from the learning activity in the same way "reward" system games do. Both Supercharged! and River City are examples of computer games designed for learning that have enjoyed some success for learning outcomes. However, the motivation attributes of each of these games were not necessarily designed to be balanced with the instructional activities, and some disconnect was reported with how students approached their designed learning activities and their motivation for playing.

This idea of aligning game activities with learning goals is meant to improve educational game design so that learning experiences for the players will be considered engaging from the perspective of the learner and successful from the perspective of the instructor. It addresses the problem with the first category of educational computer games by designing the games specifically with instructional objectives in mind and creating games whose primary purpose is for learning (Shelton 2005). Designing for activity-goal alignment ensures that a correct balance of game-like attributes are included for motivation, but that the activities within the game are meaningful, and therefore exist as more than just a means to an end. The game includes motivation-inducing attributes of challenge, proclivity, and uncertainty, yet directs them toward the learning goals, thus differentiating them from games within the second and third categories mentioned previously (Shelton and Wiley 2005). Gibbons and Fairweather (2000) offer similar advice when designing for instructional simulations in waves. It is important to look for alignment of activities with instructional goals, and that the design of the environment and model structure match the "action" of instructional goals. The design should ensure that problem solving in the environment offers the correct types of practice with desired instructional support. If designing and developing in a series of iterations consistent with activity-goal alignment is achieved, we theorize that the instructional game that results will be highly motivating and be useful for learning. In essence, the learning will be fun.

In short, although there is a body of evidence to build on, there is still a great deal of work to be done in designing theoretical frameworks for the design and utilization of educational games. For the present discussion, existing approaches must be re-examined in light of current research in teaching, design and learning, to take into account the difficulties with current approaches described above, and be grounded in accounts of actual use. The unit of analysis can be neither the player-learner nor the educational game itself, but must instead be the "personacting-with-mediational-means" (Wertsch, 1991), or more specifically, the learnerproblem-solving-using-games-as-tools.

\section{IMPLEMENTING ACTIVITY-GOAL ALIGNMENT}

"I quite agree with you," said the Duchess; "and the moral of that is--Be what you would seem to be--or if you'd like it put more simply--Never imagine yourself not to be otherwise than what it might appear to others that what you were or might have 
been was not otherwise than what you had been would have appeared to them to be otherwise."

"I think I should understand that better," Alice said very politely, "if I had it written down: but I can't quite follow it as you say it."

To this point I have asserted that communities of learners who use simulations and games exist and the practices of these communities have made an impact within educational research. In this section I present a brief example of an interaction from such a learner, comment on the example in terms of the obstacles described above, and compare the case to current educational games approaches. In this way, I endeavour to explain more clearly the potential impact of designing educational games through activity-goal alignment.

\section{Interactive fiction: an appropriate medium for alignment}

Games can exist within virtual worlds or environments that can give the player a feeling of presence with high levels of engagement (McMahan, 2003). Games have been utilized to address different types of learning as well as a variety of subject matter ranging from history to engineering and mathematics (Squire et al 2004, Shaffer et al, 2004). The interactive nature of games lends itself readily to a supporting role in teaching. One exciting possibility is the use of games in experiencing a classic text in a new media form. Interactive fiction (IF) is a new media form that provides players the opportunity to experience text in a way that provides a blend of entertainment and education.

Generally, IF is a game format that tells a narrative or story by offering a textbased description of a series of locations, non-player characters and rich description. The player interacts with the narrative through a computer program that parses the text responses of the player and advances the game accordingly. The player is a character within the story and the story progresses as a consequence of the actions of the player. Traditional IF games have come in the form of "text adventures" such as the Zork trilogy and Hitchhiker's Guide to the Galaxy in the early 1980s, but there remains a faithful subculture of writers and programmers of IF to this day. In the majority of IF games there are numerous puzzle-solving scenarios that help the player advance within the narrative. Consequently, IF requires that the player gives more attention to thought than to action. (Granade, 2005) IF also creates an explorable world that is experienced through text (Short, 2005). The nature of IF and its potential to experience traditional text in new ways make it a suitable candidate for learning experiences using classic works of fiction. Montford offers the opinion that one clear match between IF and classic texts is the idea of "text-in and text-out." The interface of IF in its text-based form offers a basic level of symmetry, consistent with experiencing text in its native paper-andink format (Deshrill, 2004, Montfort, 2003). 
SHELTON

Additionally, IF can provide successful learning experiences with classic texts by reinforcing and augmenting the instructional aims of a standard English classroom. Reading comprehension and fluency, poetic devices, literary analysis, character motivation, and examination of narrative and plot structure can all be explored. IF can offer the benefit of maintaining the original published form of the text. It may not be necessary to edit, condense, or otherwise alter the original text. Along with traditional learning goals, we feel that it is possible to experience further learning outcomes that may be unintended but nonetheless beneficial to the player. These outcomes include problem solving, spatial reasoning, and increased confidence. IF is portable as well as scalable so that it may be incorporated into classroom activity, group-work, or as a stand-alone product for an individual. Ladd (2006) has written that using IF to teach computer science has resulted in positive outcomes by teaching programming fundamentals combined with creating a project that is both motivating and difficult. We suggest that instructional technologists, armed with activity-goal alignment theory as their guiding tenet will be able to incorporate IF with classic text instruction for English.

Case example: Voices of Spoon River

The following excerpt is taken from the Voices of Spoon River project within the Creative Learning Environments Laboratory at Utah State University (http://cle.usu.edu/CLE_IF_VOSR.html). Students of a $9^{\text {th }}$ grade English class studied early $20^{\text {th }}$ century American poetry through the use of an educational game. Secondary learning goals include aspects problem solving. Highlighted here is an example analysis of two students interacting with an educational game. Portions of the interaction have been removed in order to preserve space. A screen capture of the interface is pictured in Figure 1. 
DESIGNING FOR ACTIVITY-GOAL ALIGNMENT

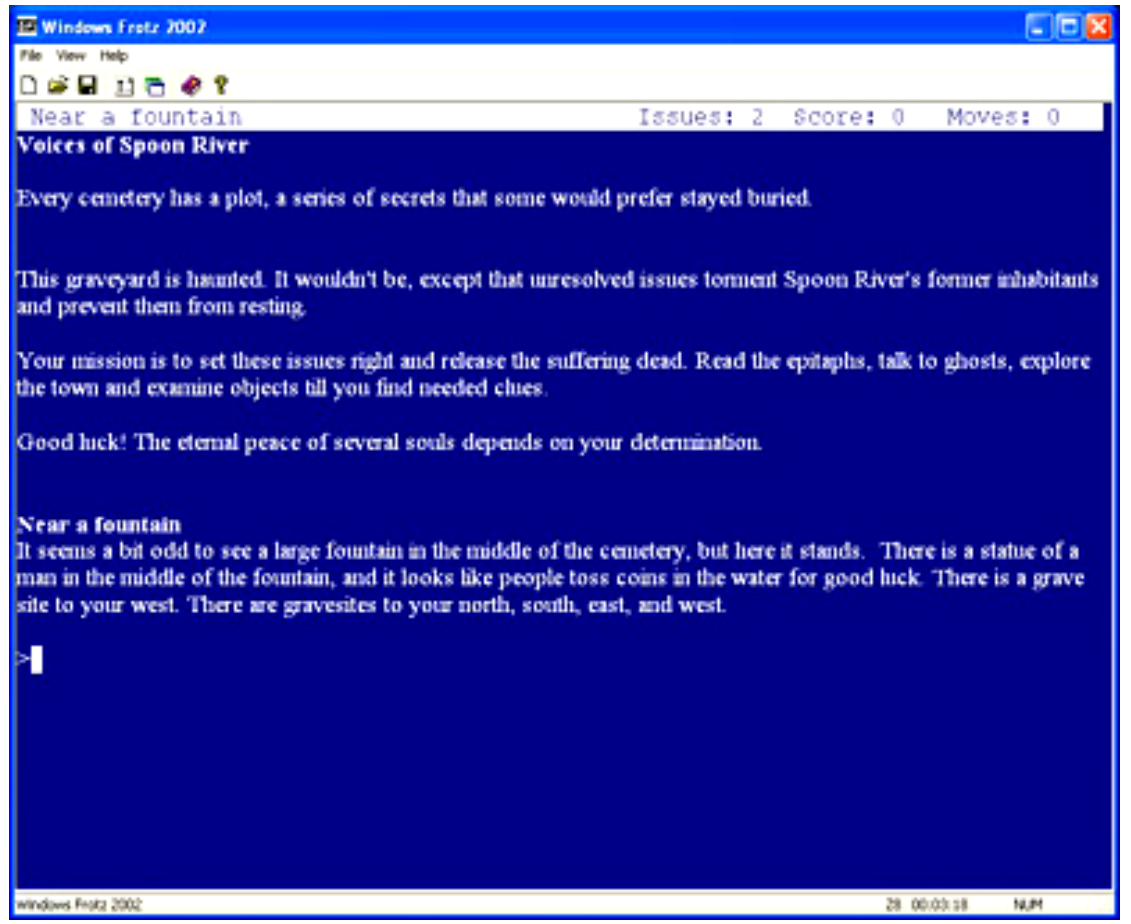

Figure 1. Voices of Spoon River interface.

In these examples we see a modified form of the problem solving process described by Nelson (1999).

- Learners negotiate a common understanding of the problem through a series of questions and restatements,

- learners' problem solving are implied, as each learner considers the problem and responds with further clarifications, thoughts, or ideas through their actions,

- learners gather information from a variety of sources, including nonplayer characters (NPCs), "help" directives, other players and initial documentation,

- a solution is attempted, and further questions are raised, beginning the problem-solving cycle anew.

I led the research team in studying how students' problem solving goals aligned with their game activity to help us determine whether or not they achieved the designed learning outcome. In this case, we first examined the "Judge Somers 
SHELTON

issue" as outlined in Table 1 below. We identified expected outcomes as designed by the game developers and unexpected outcomes as performed by students.

Table 1. Examples of learning goals, game-based activity and the activity outcome

\begin{tabular}{|c|c|c|}
\hline Game-based activity & $\begin{array}{l}\text { Learning } \\
\text { activity }\end{array}$ & Activity outcome \\
\hline Find Somers as a NPC. Put & Problem solving & Expected: Students \\
\hline $\begin{array}{l}\text { him in the cemetery, where } \\
\text { he currently has an } \\
\text { unmarked grave. }\end{array}$ & $\begin{array}{l}\text { Recognizing and } \\
\text { acting upon symbolic } \\
\text { references }\end{array}$ & $\begin{array}{l}\text { used a wheelbarrow to } \\
\text { haul and dump it on an } \\
\text { empty spot to mark the } \\
\text { Judge's plot. }\end{array}$ \\
\hline $\begin{array}{l}\text { Solve poetry puzzle in order } \\
\text { to get clues and solve issue } \\
\text { for Somers }\end{array}$ & $\begin{array}{l}\text { Reading } \\
\text { comprehension: } \\
\text { understanding } \\
\text { literary terms and } \\
\text { character analysis }\end{array}$ & $\begin{array}{l}\text { Unexpected: One } \\
\text { student tried pushing } \\
\text { the wheelbarrow up } \\
\text { some stairs because she } \\
\text { thought the Judge was } \\
\text { located there. }\end{array}$ \\
\hline
\end{tabular}

By reviewing the game transcripts, we could see what each student did during game play. Judge Somers is buried in an unmarked grave. To resolve his issue, players need to find a tombstone and take it to his unmarked grave. In the course of the game, players will encounter the judge in a photography studio where he appears to stop them from going up some stairs until they first resolve his issue. After the judge gives the instructions, he disappears. Because of this experience, Maria, a student player, thought that the judge's ghost was upstairs. From her game transcript, we recognize that she tried multiple times to push the wheelbarrow with the tombstone in it up the stairs. In her interview she was asked why she did this, to which she replied, "I didn't know where the tombstone was supposed to go. I thought that it had to go to the ghost but it didn't; it had to go to the empty spot." She left the wheelbarrow there for a while and explored other regions of the game. After finding the empty spot in the graveyard, she made the connection that this was the place for the tombstone. She then went directly to the wheelbarrow and pushed it to the unmarked grave and resolved the judge's issue.

Even though Maria performed an unexpected outcome, she was able to finally resolve the issue. However, another student did perform what the designers expected for this issue. Melissa was able to find the clues and solve the problems that lead her to ultimately resolve Judge Somers'. In her interview, Melissa talked about how the activities of the game helped her understand what items needed to be used and what action was required to resolve the issue. She talked about how walking around the town of Spoon River helped her make connections between items and the actions that needed to be performed to resolve the issue. "I would go through and I would first read an epitaph and something wouldn't make sense, but 
then I would go through the game and I would find an object and think, 'Oh, that is what it's for,' and then it would come together and then I would understand it."

Both of these students demonstrated a functioning example of the problem solving process by aligning their game play actions with the instructional goals of the exercise (Nelson, 1999; Shelton, 2005a). Because Maria had not yet performed all game activity needed to find necessary information, she had come to the incorrect conclusion of taking the tombstone to the ghost of Judge Somers and not the empty gravesite. However, Melissa had performed all of the necessary game activities and achieved the correct solution. Although their methods were different, they both demonstrated that game activity lead to fulfilling learning objectives, specifically, resolving the "problem" of Judge Somers.

Parras and Bizzocchi (2005) discuss the importance of reflective activity as also aligned with game play, and thus within the course of achieving instructional goals:

In educational game design it is important to ensure that learning takes places within the realm of play, even if learning is only made possible through reflection. To do so, reflection must appear to the learner as one of the many in-game goals that drive the game-play.

There exists some evidence suggested by the transcripts of in-game reflection of character motivations and connections with one another, in fact, the genre itself allowed for such reflection due to its nature of having to wait for player input for narrative progression (Scoresby, Duncan \& Shelton, 2006). It may very well be the case that the game genre itself dictates the effectiveness of activity-goal alignment during game play, a point recently discussed by Dickey (2006) and worth further exploration for subsequent study.

\section{Discussion of the sample case and current educational games approaches}

We address the question of aligning the structure of the games with the learning objectives by examining the challenges faced by learning technologists. Researchers who have studied the integration of computer games designed as part of an instructional exercise have reported their success and limitations. Further studies continue to investigate new ways of implementing computer games as teaching tools in both formal and informal learning environments (Gee, 2003; Shaffer et al., 2004). Designers of educational games must address issues concerning the format of game play and how to avoid attributes that may distract from the learning activities. So what are the primary design issues instructional technologists face when beginning their design? Brown and Duguid (Brown \& Duguid, 2000) suggest that learning about something is limited to gaining information, whereas learning to become something requires both information and experience. For example, learning about being a doctor and learning to become a doctor are two very different things. When designing games, instructional technologists should try to design instructional tools that help the learner to become something. Being an active participant in one's learning in an educational 
game is assisted by aligning the game's activities with the intended instructional goals.

Aligning game activities with learning goals is meant to improve educational game design so that learning experiences will be considered engaging from the learner's perspective and successful from the instructor's perspective. It addresses the problem with the first category of educational games by designing specifically with instructional objectives in mind and creating games whose primary purpose is learning (Shelton, 2005b). Designing for activity-goal alignment ensures that a correct balance of game-like attributes are included for motivation, but that the activities within the game are meaningful, and therefore exist as more than just a means to an end. The game in this example case includes motivation-inducing attributes of challenge, proclivity, and uncertainty, yet directs them toward the learning goals, thus differentiating them from games within the second and third categories mentioned previously. It is important to look for alignment of activities within instructional goals, and to match the "action" of instructional goals with the design of the environment and model structure. The design should ensure that problem solving in the environment offers appropriate types of practice with desired instructional support. If designing and developing in a series of iterations consistent with activity-goal alignment is achieved, I theorize that the resulting educational game will be highly motivating and useful for learning. In essence, the learning will be more like "fun" even if it is not the same as the kinds of activity associated with most commercially successful games.

The sample case includes a small number of learners, yet scalability (in terms of simulation-game-bandwidth) is not an issue. Learners are provided with meaningful learning support "anytime anywhere" within the games, yet most cases are rich with human-to-human interaction. Educational games are successfully embedded in meaningful learning contexts, but the design, development and use of them is done by humans for other humans. It is because that play within these scenarios is naturally occurring and exists in environments of social interaction that the resulting activity can be deemed as significant.

\section{ROLE OF PRESENCE AND FLOW}

SHE took her off the table as she spoke, and shook her backwards and forwards with all her might. The Red Queen made no resistance whatever: only her face grew very small, and her eyes got large and green: and still, as Alice went on shaking her, she kept on growing shorter--and fatter--and softer--and rounder-and-and it really was a kitten after all.

Perspective certainly counted for something when Alice awoke from her experience in Wonderland. In the same vein, the kinds of learning experiences through virtual interfaces in simulation game environments impact their design and use. In Voices of Spoon River, we chose an interface of text-based input and output 
to help reflect the kinds of literacy objectives we were trying to achieve, matching those of state and national standards. Subsequently, we built $\operatorname{VOSR} 3 D$, a 3D version of the same game but whose interface could be set to either first-person or third person perspective (see Figure 2). The textual components of both the original Voices of Spoon River and VOSR 3D were consistent in terms of object use and description, and therefore the game play was consistently aligned in both versions with the primary learning objectives. Yet the games would appear to be very different in how the player interacted with the environment in each version. By changing the learner's perspective of the game, we undoubtedly altered the way the learner came to understand the information as gleaned from the virtual environment. The issues of flow, presence and immersion continue to effect the way games are experienced, even when keeping the design philosophy of activitygoal alignment intact.

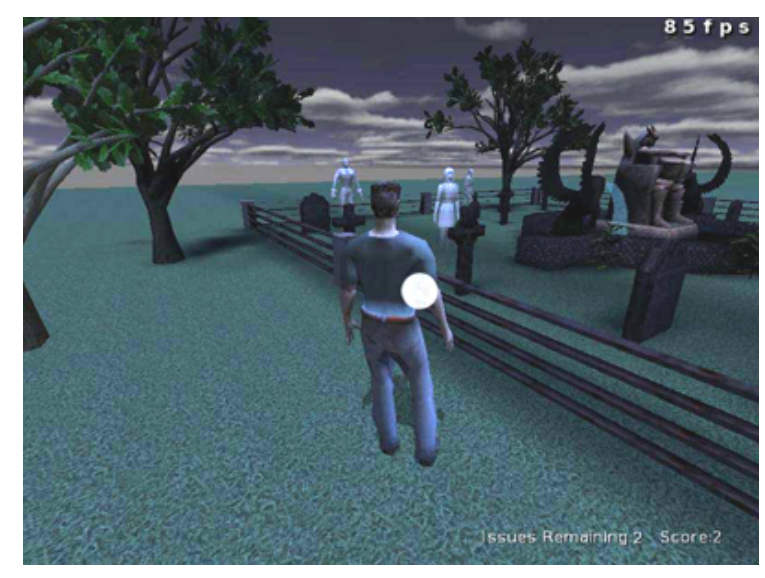


SHELTON

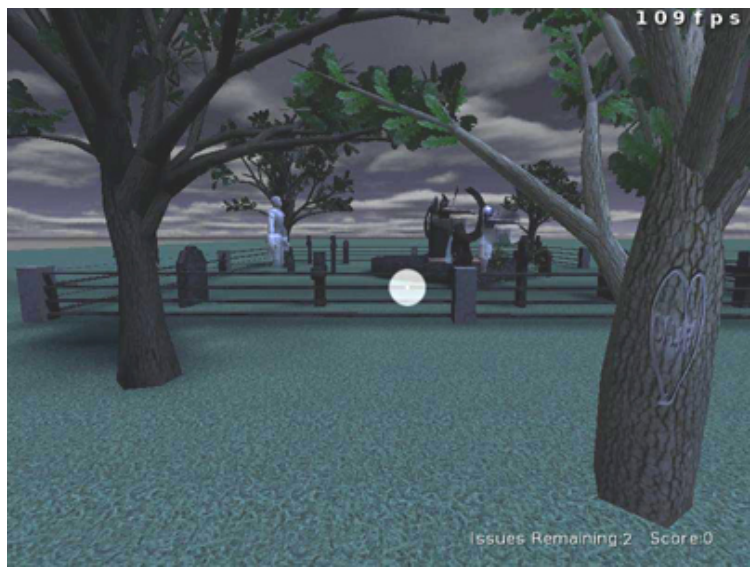

Figure 2. Screenshots of VOSR 3D in third-person perspective (above) and first-person perspective (below).

Researchers have consistently referred to the link between presence, the sense of "being there" in an environment, and positive learning outcomes despite the variations among the learning activities that take place in virtual environments and the different kinds of virtual reality interfaces (Azuma, 1997; Hedley, Billinghurst, Postner, May, \& Kato, 2002; Winn \& Windschitl, 2002). Researchers generally acknowledge that immersion, the extent to which the computer system delivers a surrounding environment, is a vital element in contributing to the sense of presence and therefore may also be linked to positive learning outcomes. Yet, Slater (Slater, 1999) warned that researchers and educators should not assume presence is positively correlated to task performance. Research is needed to explore the nature of immersive technology and presence with regard to their roles in learning activities. The notion of flow, or the state of being cognitively engrossed by an activity, is also linked with positive learning outcomes and is often confounded with issues of presence within the research literature (Csikszentmihalyi, 1988; Witmer \& Singer, 1998). In order to explore the nature of presence and flow in immersive systems, it is necessary to find how different viewing perspectives impact them given the wide range of technology that is available and in use.

Since the application of artificial or computer-generated environments as learning contexts, researchers have questioned the effects of presence and immersion in learning activities (Hedley et al., 2002; Sheridan, 1992; Winn, 2002). Some early results indicated a "link" between presence and student learning, with correlations between positive learning outcomes and students' self-reports of degrees of presence (Witmer \& Singer, 1998). High levels of presence may involve the focusing on a task within the virtual environment, or contrarily, high levels of presence may involve the perception of being enveloped, thus being acutely aware 
of the perceived environment regardless of task. Understanding the nature of presence in virtual environments has been further compounded by a number of studies that are based on the assumption that the positive correlation between presence and learning is a given, regardless of the type of virtual environment or the type of administration of the learning activity (Fjeld, Schar, Signorello, \& Krueger, 2002; Winn, Windschitl, Fruland, \& Lee, 2002; Woods \& Billinghurst, 2003).

For a more consistent focus of conversation around these points, the characterization of immersion should be agreed upon as the extent to which the computer system delivers a surrounding environment, one that blocks sensations from the real world, accommodates many sensory modalities, and has rich representational capability (Slater, 1999; Slater \& Wilbur, 1997). By changing viewing perspectives of the game play activity within desktop environments from $1^{\text {st }}$ person, $3^{\text {rd }}$ person, and "none" perspectives (text-based) we are changing the relative "immersiveness" of the system. The sense of presence is defined as the feeling of being in an environment even if one is not physically there. The feeling of presence is also congruent with the environment and the situation within that environment (Robillard, Bouchard, Fournier, \& Renaud, 2003). When someone is focused on the situation they become aware of what is in their environment. Being able to focus and recognizing the artifacts within the environment help add to the sense of presence (Fontaine, 1992). The measurements of flow are involvement, concentration, loss of sense of time, loss or lack of self-consciousness, and a feeling of superiority. These measures of flow all lead to an intrinsically rewarding experience (Csikszentmihalyi, 1988). To reach a substantive state of flow, a person's skills have to be adequate to deal with the challenges of the situation (Hargadon, 2001); (Slater, 2003) If the skill level is too low, a person will not reach this state of flow due to frustration of not performing at a desired skill level. Some researchers have said that presence and emotion are not connected. Others have said that emotions are how we experience our environment and that emotions may play a role both as a way of determining and a cause of the feeling of presence (Baños et al., 2003). The emotional nature of the experience is a factor that needs to be investigated with the intention of establishing relationships to both presence and flow.

Studies such as those begun by Taylor (2003) are needed to determine the cognitive effects that immersion, presence and flow have on a learning activity with a specific gaming viewing perspective. The results will be useful in formulating further inquiry into the design of effective learning tools using virtual $3 \mathrm{D}$ environments. By developing and using a consistent set of terms, researchers will be provided with a more useful means to communicate results across research venues and within scientific literature. Future studies of learning with artificial and gaming environments may be more likely to be based on a shared vocabulary with consistent meanings to communicate (a) what cognitively is happening with students as they interact with virtual/real objects and environments and (b) what aspects of mixed-reality and virtual interfaces afford different uses among learners. 
SHELTON

Based in part on those results, additional phases of research can help to substantiate the claims of presence and flow for new educational games.

Therefore, two vital research questions are:

- How does the viewing perspective of the player impact his/her feeling of presence and flow? By considering current frameworks for researching the relationships between immersion, presence, flow and learning and applying these frameworks to a more broadly defined set of virtual environments (Bystrom, Barfield, \& Hendrix, 1999), the objective is to refine and inform future research with improved terminology.

- What, if any, are the links between learning strategies, presence, and flow in a designed learning exercise using computer games with different viewing perspectives?

To address these questions, investigations are needed to determine what role viewing perspective plays within immersive environments for game players to reach a substantive level of presence or flow. This work has begun (see Scoresby \& Shelton 2007) using a qualitative analysis of responses to interview questions and an analysis of students' videotaped activities to help identify relationships between cognitive states and the learners' interactions with virtual objects. Ultimately, the findings of this and other needed research in this area will help to clear the confusion in the field by clarifying the roles of presence and flow within learning activities, and provide a consistent vocabulary across future research with regard to various gaming environments.

\section{THE FUTURE FOR ACTIVITY-GOAL ALIGNMENT, RESEARCH AND PRACTICE}

Alice asks The Cheshire Cat: "Would you tell me, please, which way I ought to go from here?"

The Cat responds, "That depends a good deal on where you want to get to." Alice replies, "I don't much care where so long as I get somewhere."

"Oh, you're sure to do that," says the Cat, "if you only walk long enough."

In a move toward extending existing efforts that are emerging from computer games studies, I see three areas of research outcomes needed from the proposed ideas within this chapter: the development of design and utilization frameworks, the application of those frameworks, and the development of new resources using activity-goal alignment.

Development of educational games design and utilization frameworks and techniques.

The first product of ongoing research should be a group of theoretical frameworks and strategies for designing and creating educationally effective simulations and 
games that are accessible to all individuals. Research should help determine the effectiveness of the games across all populations of students in accordance with activity-goal alignment to further assess the success of their use in meeting educational standards. This research should build upon previous work in educational simulation design approaches and in teaching theory and design of educational games.

\section{Application of the frameworks.}

Second, in parallel to framework development, game development is needed with application of the frameworks to substantiate guidelines for the accessible design of educational simulations and games. These guidelines will parallel the effort of accessibility principles currently in effect and will be grounded in practices identified and studied through the framework development portion of ongoing research. The effort should include tracking the progress in the design and development of established simulations already in-use to refine recommendations and standards for instructional computer game accessibility for commercial and non-commercial development.

\section{Development of new and existing resources for creating educational games.}

Many of the existing resources identified in the application of frameworks should be used as projects to re-work with the created compliance activity-goal alignment guidelines. A number of projects are eligible for remixing through this work, including those within the NSDL repository and those available from OpenCourseware initiatives such as MIT OCW. As new projects surface, development is needed to create resources for building instructional computer simulation games that address learning issues within formal education environments and are aligned with state and national standards. The effort is to offer appropriate versions of the games that are accessible to a vast range of students who would not normally be able to engage with them.

\section{SUMMARY}

Last year, I received a phone call from a group of high school educators and administrators from the "four corners" region of Utah. They were addressing issues and resources related to the NSF Star Schools grant application with the hope of achieving a technological infrastructure for their rural and underprivileged population of students. "We have a question," they said. "A criteria in the Star Schools RFP states that our proposal must have a plan to implement "simulations and games' within our curriculum. How do we do that? What should we do?" Like the emails from teachers mentioned in the Introduction who asked me how to implement educational games within their classrooms, I did not have an informed answer to many of their questions. With the ideas and agenda proposed within the pages of this and other chapters of this volume, we as technologists, game 
designers, and educators have the opportunity to address more of these challenges and provide more of the answers. There may be many ways to discover some of the answers. The approach I argue is for instructors and game designers alike to develop and understand their instructional objectives before they begin game design, and then make sure to align their game activities with those objectives. Perhaps this requires a new view on the old "objectives-plus-aligned-curricularmaterials" view of classic instructional design.

At the beginning of this chapter I asserted that the main interest in computerbased simulations and games was in their ability to facilitate flexible delivery of complex information while maintaining high levels of motivation. I argued that despite the existence of a variety of approaches to designing worthwhile educational games, a number of them have not met educational expectations and that new frameworks were needed for their design and use. This gap in effective approaches is extremely evident in the case of persons with varying abilities, whose population of students suffers from a lack of empirical attention in this field. However, the process of designing games by aligning the game play activity with the instructional objectives is a promising beginning. It is through the presentation of the educational game case of learning problem solving skills, along with the presentation of evolving analytic techniques to study learning through student activity that I hope to have explained the merit of this design approach. I then presented an example of an educational game used to facilitate learning in a problem-solving context that was built with activity-goal alignment. I suggested that an approach of ethnographic study of the use and mediated understandings of simulation game tools was appropriate to study how students achieved positive learning outcomes, and the challenges of design were worth the benefits to students who played the game. The ethnographic studies are an appropriate and effective strand of research to help create guidelines for eventual compliance standards by Federal, State and local agencies. Re-working the guidelines into existing and new products, along with the presentation of these results to a wide audience through conferences and publications, provides a means to influence a wide audience. It is through this discussion I hope to have made explicit the kind of impact this kind of continuing research will have on the educational, instructional and technology design communities.

I believe that a more rigorous understanding of the ways educational games function in these existing, interaction-rich communities will provide the basis for instructional strategies with the potential to revolutionize learning for gamers. Following a more focused plan, the future of educational game research activity will work to implement recommendations into new and existing educational tools. Specifically, the research will shed significant light on the role of educational games in education, and will provide solid grounding to a long-term research agenda dedicated to understanding the effects and potential benefits of technology on learning. 


\section{REFERENCES}

BECTA (British Education Communications and Technology Agency) (2001). Computer games in education project. Retrieved July 15, 2005, from http://www.becta.org.uk/research/research.cfm?section=1\&id=2826

Azuma, R. T. (1997). A survey of augmented reality. Presence, 6(4), 355-385.

Baños, R. M., Botella, C., Alcañiz, M., Liaño, V., Guerrero, B., \& Rey, B. (2003). Immersion and emotion: Their impact on the sense of presence. Cyberpsychology \& Behavior, 6(5), 467-476.

Barab, S. A., Hay, K. E., Barnett, M., \& Keating, T. (2000). Virtual Solar System project: Building understanding through model building. Journal of Research in Science Teaching, 37(7), 719-756.

Barab, S. A., Hay, K. E., Barnett, M., \& Squire, K. (2001). Constructing virtual worlds: Tracing the historical development of learner practices. Cognition and Instruction, 19(1), 47-94.

Barrows, H. S. (1986). A taxonomy of problem-based learning methods. Medical Education, 20(6), 481-486.

Barrows, H. S. (1996). Problem-based learning in medicine and beyond: A brief overview. New Directions for Teaching and Learning, 68, 3-12.

Barrows, H. S. (2002). Is it truly possible to have such a thing as dPBL? Distance Education, 23(1), $119-122$

Blum, T., \& Yocom, J. (1996). A fun alternative: Using instructional games to foster student learning. Teaching Exceptional Children, 29(2), 60-63.

Blumenfeld, P., Fishman, B., Krajcik, J., \& Marx, R. W. (2000). Creating usable innovations in systemic reform: Scaling up technology-embedded project-based science in urban schools. Educational Psychologist, 35(3), 149-164.

Brown, J. S., \& Duguid, P. (2000). Learning - In Theory and in Practice. In The social life of information (pp. 117-146). Cambridge, MA: Harvard Business School Press.

Bystrom, E. K., Barfield, W., \& Hendrix, C. (1999). A conceptual model of the sense of presence in virtual environments. PRESENCE: Teleoperators and Virtual Environments, 8(2), 241-245.

Christensen, C. A., \& Gerber, M. M. (1990). Effectiveness of computerized drill and practice games in teaching basic math facts. Exceptionality, 1(3), 149-165.

Conderman, G., \& Tompkins, B. J. (1995). State the facts. Teaching Exceptional Children, 27(3), 5758 .

Csikszentmihalyi, M. (1988). The flow experience and human psychology. In M. Csikszentmihalyi \& I. S. Csikszentmihalyi (Eds.), Optimal Experience (pp. 364-383). Cambridge, UK: Cambridge University Press.

Cuban, L. (1986). Teachers and machines: The classroom use of technology since 1920. New York: Teachers College Press.

Davison, A., \& Gordon, P. (1978). Games and simulations in action. Great Britain: Woburn Press.

Dede, C. (1995). The evolution of constructivist learning environments: Immersion in distributed, virtual worlds. Educational Technology, 35(5), 46-52.

deJong, T., \& vanJoolingen, W. R. (1998). Scientific discovery learning with computer simulations of conceptual domains. Review of Educational Research, 68(2), 179-201. 
SHELTON

Dickey, M. D. (2006). Game design narrative for learning: Appropriating adventure game design narrative devices and techniques for the design of interactive learning environments. Educational Technology Research \& Development, 54(3), 245-263.

Diggs, C. S. (1997). Technology: A key to unlocking at-risk students. Learning and Leading with Technology, 25(2), 38-40.

Fawcett, L. M., \& Garton, A. F. (2005). The effect of peer collaboration on children's problem-solving ability. British Journal of Educational Technology, 75(2), 157-169.

Fishman, B., Marx, R. W., Blumenfeld, P., \& Krajcik, J. (2004). Creating a framework for research on systemic technology innovations. The Journal of the Learning Sciences, 13(1), 43-76.

Fjeld, M., Schar, S. G., Signorello, D., \& Krueger, H. (2002,). Alternative tools for tangible interaction: A usability evaluation. Paper presented at the IEEE and ACM International Symposium on Mixed and Augmented Reality (ISMAR), Darmstadt, Germany.

Fontaine, G. (1992). The experience of a sense of presence in intercultural and international encounters. PRESENCE: Teleoperators and Virtual Environments, 1(4), 482-490.

Gee, J. P. (2003). Semiotic domains: Is playing video games a "waste of time"? In What Video Games Have to Teach Us about Learning and Literacy. New York: Palgrave MacMillan.

Gordin, D. N., \& Pea, R. D. (1995). Prospects for scientific visualization as an educational technology. The Journal of the Learning Sciences, 4(3), 249-279.

Gunter, B. (1998). Tapping into players' habits and preferences. In The Effects of video games on children: The myth unmasked (pp. 29-48). Sheffield, England: Sheffield Academic Press.

Hargadon, D. Y. (2001). The pleasures of immersion and engagement: Schemas, scripts and the fifth business. Digital Creativity, 12(3), 153-166.

Hayes, E. (2002). Find out who you really are: Adult learning in virtual worlds. Paper presented at the Adult Education Research Conference (AERC), North Carolina State University, Raleigh, NC.

Hedley, N. R., Billinghurst, M., Postner, L., May, R., \& Kato, H. (2002). Explorations in the Use of Augmented Reality for Geographic Visualization. PRESENCE: Teleoperators and virtual environments.

Hertel, J. P., \& Millis, B. J. (2002). Using simulations to promote learning in higher education. Sterling VA: Stylus Publishing.

Holland, W., Jenkins, H., \& Squire, K. (2003). Chapter 1: Theory by design. In M. J. P. Wolf \& B. Perron (Eds.), The video game theory reader (pp. 25-46). New York: Routledge.

Jonassen, D. H., Peck, K. L., \& Wilson, B. G. (1999). Learning by reflecting: What have we learned? In Learning with technology: A constructivist perspective (pp. 217-231). Upper Saddle River, NJ: Merrill.

Jones, K. (1987). Simulations: A handbook for teachers and trainers (2 ed.). Great Britain: Kogan Page. Kirriemuir, J. (2002). Video gaming, education and digital learning technologies. D-Lib Magazine, 8.

Kirriemuir, J. (2003). The relevance of video games and gaming consoles to the higher and further education learning experience. Retrieved July 15, 2005, from www.ceangal.com

Kirriemuir, J., \& McFarlane, A. (2003). Use of computer and video games in the classroom. Paper presented at the DiGRA, Utrecht, Holland.

Lepper, M. R., \& Chabay, R. W. (1985). Intrinsic motivation and instruction: Conflicting views on the role of motivational processes in computer-based education. Educational Psychologist, 20(4), 417430. 


\section{DESIGNING FOR ACTIVITY-GOAL ALIGNMENT}

Malone, T. W. (1980). What makes things fun to learn? Unpublished Ph.D. Dissertation, Stanford University, Stanford, CA.

Malone, T. W., \& Lepper, M. R. (1987). Making learning fun: A taxonomy of intrinsic motivations for learning. In R. E. Snow \& M. J. Farr (Eds.), Aptitude, learning and instruction Volume 3: Conative and affective process analysis. Englewood Cliffs, NJ: Erlbaum.

Moshell, J. M., \& Hughes, C. E. (1995). The virtual academy: A simulated environment for constructionist learning (No. JMM95.23): University of Central Florida.

Nelson, L. M. (1999). Collaborative problem solving. In C. M. Reigeluth (Ed.), Instructional design theories and models: A new paradigm of instructional theory (pp. 241-267). Hillsdale, NJ: Lawrence Erlbaum Associates.

Okolo, C. M. (1992). The effect of computer-assisted instruction format and initial attitude on arithmetic facts proficiency and continuing motivation of students with learning disabilities. Exceptionality, 3(4), 195-211.

Paras, B., \& Bizzocchi, J. (2005). Game, motivation, and effective learning: An integrated model for educational game design. Paper presented at the Digital Games Research Association (DiGRA): Changing Views -- Worlds in Play, Vancouver, BC.

Robillard, G., Bouchard, S., Fournier, T., \& Renaud, P. (2003). Anxiety and presence during VR immersion: A comparative study of the reactions of phobic and non-phobic participants in therapeutic virtual environments derived from computer games. Cyberpsychology \& Behavior, 6(5), 467-476.

Roschelle, J. M. (1992). Learning by collaborating: Convergent conceptual change. The Journal of the Learning Sciences, 2(3), 235-276.

Roschelle, J. M., Pea, R. D., Hoadley, C. M., Gordin, D. N., \& Means, B. M. (2000). Changing how and what children learn in school with computer-based technologies. The Future of Children, 10(2), 76101.

Scoresby, J., Duncan, S. M., \& Shelton, B. E. (2006). Voices of Spoon River: Exploring early American poetry through computer gaming. Paper presented at the Games, Learning \& Society 2006, Madison, WI.

Scoresby, J. \& Shelton, B. E. (2007). Visual perspectives within educational computer games: Effects on presence and flow within virtual learning environments. Paper presented at the American Educational Research Association (AERA) Conference, 2007, Chicago, IL.

Shaffer, D. W., Squire, K. R., Halverson, R., \& Gee, J. (2004). Video games and the future of learning. Retrieved October 20, 2005, from http://www.academiccolab.org/resources/gappspaper1.pdf

Shelton, B. E. (2003). How augmented reality helps students learn dynamic spatial relationships. Unpublished Doctoral Dissertation, University of Washington, Seattle.

Shelton, B. E. (2005a). Designing and creating interactive fiction for learning. Paper presented at the New Media Consortium (NMC) Online Conference on Educational Gaming, Internet.

Shelton, B. E. (2005b). Designing and developing instructional games: A project to align learning activity with instructional goals. Retrieved October 25, 2005, from http://it.usu.edu/cle/CLE_alignment.htm

Shelton, B. E., \& Wiley, D. (2006a). How do I get in the game?: The papers, projects, and practices of teaching educational games. Paper presented at the Games, Learning \& Society 2006, Madison, WI. 
SHELTON

Shelton, B. E., \& Wiley, D. (2006b). Instructional designers take all the fun out of games: Rethinking elements of engagement for designing instructional games. Paper presented at the American Educational Research Association (AERA) 2006, San Francisco.

Sheridan, T. B. (1992). Musings on telepresence and virtual presence. PRESENCE: Teleoperators and Virtual Environments, 1(1), 120-125.

Shiah, R.-L., Mastropieri, M. A., Scruggs, T. E., \& Fulk, B. J. M. (1994). The effects of computerassisted instruction on the mathematical problem solving of students with learning disabilities. Exceptionality, 5(3), 131-161.

Slater, M. (1999). Measuring presence: A response to the Witmer and Singer questionnaire. PRESENCE: Teleoperators and Virtual Environments, 8(5), 560-566.

Slater, M. (2003). A note on presence terminology, from http://presence.cs.ucl.ac.uk/presenceconnect/articles/Jan2003/melslaterJan27200391557/melslaterJa n27200391557.html.

Slater, M., \& Wilbur, S. (1997). A framework for immersive virtual environments (FIVE): Speculations on the role of presence in virtual environments. PRESENCE: Teleoperators and Virtual Environments, 6(6), 603-616.

Soloway, E., Jackson, S. L., Klein, J., Quintana, C., Reed, J., Spitulnik, J., et al. (2001). Learning theory in practice: Case studies of learner-centered design: HI-CE, University of Michigan.

Squire, K. (2002). Cultural framing of computer/video games. Game Studies, 2(1).

Squire, K., Barnett, M., Grant, J. M., \& Higginbotham, T. (2004). Electromagnetism supercharged! Learning physics with digital simulation games. Paper presented at the International Conference of the Learning Sciences 2004 (ICLS 04), Santa Monica, CA.

Steinkuehler, C. A. (2003). Videogaming as participation in a discourse. Paper presented at the Annual Conference of the American Association for Applied Linguistics.

Steinkuehler, C. A., \& Chmiel, M. (2006). Fostering scientific habits of mind in the context of online play. Paper presented at the 7th International Conference of the Learning Sciences, Bloomington, IN.

Suchman, L. (2000). Located accountabilities in technology production. Retrieved June 27, 2001, from http://www.comp.lancs.ac.uk/sociology/soc0391s.html

VanEck, R. (2006). Where do we go from here? Ten critical areas to guide future research in digital games-based learning. Paper presented at the Games, Learning \& Society 2006, Madison, WI.

Welch, M. (1995). It's in the bag: An instructional game to promote positive student attitudes toward writing. Teaching Exceptional Children, 27(2), 63-65.

Wertsch, J. V. (1991). Voices of the mind. Cambridge, MA: Harvard University Press.

Windschitl, M. (2000). Supporting the development of science inquiry skills with special classes of software. Educational Technology Research \& Development, 48(2), 81-95.

Winn, W. (2002). Learning in artificial environments: Embodiment, embeddedness and dynamic adaption. Technology, Instruction, Cognition and Learning, 1(1), 87-114.

Winn, W., \& Windschitl, M. (2002). Strategies used by university students to learn aspects of physical oceanography in a virtual environment. Paper presented at the American Educational Research Association, New Orleans, LA. 
DESIGNING FOR ACTIVITY-GOAL ALIGNMENT

Winn, W., Windschitl, M., Fruland, R., \& Lee, Y. (2002). When does immersion in a virtual environment help students construct understanding? Paper presented at the Internactional Conference on the Learning Sciences (ICLS), Seattle, WA.

Witmer, B. G., \& Singer, M. J. (1998). Measuring presence in virtual environments: A presence questionnaire. Presence: Teleoperators and Virtual Environments, 7, 225-240.

Woods, E., \& Billinghurst, M. (2003). Empirical study of museum learning with augmented reality. Paper presented at the Australian New Technologies 2003, Sydney, Australia.

Zimmerman, E., \& Fortugno, N. (2006). Game design essentials. Paper presented at the Games, Learning \& Society 2006, Madison, WI.

Brett E. Shelton

Department of Instructional Technology

Utah State University 